\title{
COMPARATIVE STUDY OF BUPIVACAINE WITH FENTANYL VS BUPIVACAINE WITH FENTANYL PLUS MORPHINE IN SPINAL ANAESTHESIA FOR LOWER SEGMENT CAESAREAN SECTIONS
}

\author{
Keisham Upendra Singh', Sukham Thoibahenba Singh², Sonia Nahakpam³, Linthoingambi Samjetsabam ${ }^{4}$, Zarina Waheb ${ }^{5}$, \\ Laishram Dhanachandra ${ }^{6}$
}

${ }_{1}^{1}$ Associate Professor, Department of Anaesthesiology, JNIMS, Imphal, Manipur, India. ${ }^{2}$ Associate Professor, Department of Anaesthesiology, JNIMS, Imphal, Manipur, India.

3Postgraduate Trainee, Department of Anaesthesiology, JNIMS, Imphal, Manipur, India.

${ }^{4}$ Postgraduate Trainee, Department of Anaesthesiology, JNIMS, Imphal, Manipur, India.

5Postgraduate Trainee, Department of Anaesthesiology, JNIMS, Imphal, Manipur, India.

${ }^{6}$ Postgraduate Trainee, Department of Anaesthesiology, JNIMS, Imphal, Manipur, India.

\section{BACKGROUND}

ABSTRACT

Anaesthesiologists all over the world are facing challenges to manage increasing number of caesarean deliveries. Central neuraxial techniques of subarachnoid blockade with $0.5 \%$ Bupivacaine heavy solutions in different doses are generally employed.

\section{MATERIALS AND METHODS}

Sixty parturients coming for non-urgent caesarean deliveries were randomized into 2 groups of 30 each; Group I receiving 7.5 mg Bupivacaine heavy plus $16 \mu \mathrm{g}$ Fentanyl and Group II receiving $7.5 \mathrm{mg}$ Bupivacaine heavy plus Fentanyl $16 \mu \mathrm{g} \&$ Morphine $125 \mu \mathrm{g}$, the volume of solutions being $2 \mathrm{ml}$ in both the groups.

\section{RESULTS}

Demographic data, pre-operative, intra-operative \& post-operative vitals, characteristics of motor blockade and complications were comparable in both the groups. However sensory blockade (analgesia) in Group II was much longer and post-operative analgesic consumption in the first 24 hours were much lesser in Group II.

\section{CONCLUSION}

It has been concluded that addition of Fentanyl $16 \mu \mathrm{g}$ and Morphine $125 \mu \mathrm{g}$ to Bupivacaine $7.5 \mathrm{mg}$ is a very good option for nonurgent Caesarean deliveries.

\section{KEY WORDS}

Intrathecal Morphine; Fentanyl; Bupivacaine; LSCS.

HOW TO CITE THIS ARTICLE: Singh KU, Singh ST, Nahakpam S, et al. Comparative study of bupivacaine with fentanyl vs bupivacaine with fentanyl plus morphine in spinal anaesthesia for lower segment caesarean sections. J. Evolution Med. Dent. Sci. 2018;7(48):5184-5187, DOI: $10.14260 /$ jemds/2018/1150

\section{BACKGROUND}

In the last few decades, number of caesarean birth has increased dramatically in both the developed and developing countries especially in countries like India where the actual incidence has been reported to have crossed even $40 \%$ of all deliveries in some centres.1,2 The brunt of the problem falls more on the anaesthesiologists providing anaesthesia to an apparently healthy pregnant woman whose anatomy and physiology are stretched to the maximum to provide the need for the foetus, which is in the fastest phase of human growth. 3 Regional anaesthesia employing central neuraxial blockade through lumbar subarachnoid block by injecting preservative free Bupivacaine heavy $0.5 \%$ is the most popular anaesthesia technique. ${ }^{4}$

The dose of the local anaesthetic (LA) decides the extent and duration of the block - too little dose will cause untimely

'Financial or Other Competing Interest': None.

Submission 18-10-2018, Peer Review 11-11-2018,

Acceptance 17-11-2018, Published 26-11-2018.

Corresponding Author:

Dr. Sukham Thoibahenba Singh,

Department of Anaesthesiology,

JNIMS, Imphal-795001,

Manipur, India.

E-mail: thoibas@gmail.com

DOI: $10.14260 /$ jemds $/ 2018 / 1150$ wearing away of the block, visceral pain on exteriorization of uterus \& handling of other abdominal contents, whereas too large a dose might result in an intensive block with the resultant hypotension, bradycardia and sometimes even cardiac arrest.

With a view to lower the dose of LA and to improve the quality \& duration of the sub-arachnoid block (SAB) at the same time, adjuvants like clonidine, dexmedetomidine, morphine, fentanyl etc. are added to the LA. The adjuvants like clonidine, dexmedetomidine etc. improve the quality and prolong the duration of block but the incidence of hypotension, bradycardia are still of concern.5, 6 Fentanyl, a synthetic opioid, improves the quality and duration of block but at doses like $25 \mu \mathrm{g}$, the incidence of pruritus is high, 7 and the duration of block to provide adequate postoperative analgesia is not satisfactory. Morphine, a hydrophilic opioid, when given intrathecally has a slower onset of action but prolonged analgesic effect with incidence of post-operative respiratory depression at higher doses. 8,9

A hypothesis was made that addition of fentanyl to a lower dose of Bupivacaine will enhance the onset of a smooth subarachnoid block and morphine with its slower but sustained action in the central neuraxial blockade will provide a prolonged post-operative analgesia. This clinical study was undertaken to compare the effects of $7.5 \mathrm{mg}$ of Bupivacaine heavy with a low dose of Fentanyl (16 $\mu \mathrm{g})$ alone 
on one end and addition of $125 \mu \mathrm{g}$ of Morphine to this mixture on the other end, comparing the hemodynamic parameters, maternal and foetal side-effects and duration of post-operative analgesia.

\section{MATERIALS AND METHODS}

We used a double blind randomized controlled trial. Randomization in a ratio of $1: 1$ was carried out using a computer-generated random process with concealment. Whenever a patient came in, the allocation was informed to the investigator by a third party from the Community Medicine Department of the institute. The drugs in both intervention as well as controlled arms were similar in physical characteristics, volume and were prepared by another person, who was not involved in the study. The assessors (investigators) were also blinded.

The sample size of 60 patients for the study was taken for convenience. All term (>36 weeks) singleton pregnant women opted for elective caesarean section were included in the study. Pregnant women with contraindication to subarachnoid block (SAB) with the study drugs, with morbid and comorbid conditions like PIH, eclampsia, multiple pregnancy, placenta praevia and, other systemic diseases with physical status ASA III and above were excluded. All eligible willing participants were recruited and numbered consecutively. Pregnant women posted for elective caesarean section in the Department of Anaesthesiology, between July 2018 and September 2018 had been recruited.

Parturients were cannulated with 18G canula and ringer lactate solution started. After connecting to a standard monitor to record ECG, SpO2 \& NIBP and with aseptic and antiseptic measures, the primary investigator located and punctured the dura at L3-4 level with a 25G Quincke needle while the subject was lying in right lateral decubitus position. After confirmation of free flow of CSF, the blinded primary investigator gave a mixture of the following solutions intrathecally: $1.5 \mathrm{ml}(7.5 \mathrm{mg})$ of preservative free Bupivacaine heavy $+16 \mu \mathrm{g}$ of Fentanyl in Group I and $1.5 \mathrm{ml}$ (7.5 mg) of preservative free Bupivacaine heavy $+16 \mu \mathrm{g}$ Fentanyl $+125 \mu \mathrm{g}$ Morphine in Group II. The volume of the mixture in both the groups was made $2 \mathrm{ml}$ by preparing the adjuvants in normal saline. After successful intrathecal injection, parturients were returned to supine position with a wedge under the right hip. Bladder catheterization and coloading with Ringer lactate solution $500 \mathrm{ml}$ over 5-10 minutes were initiated. Oxygen with face mask at $4 \mathrm{~L} / \mathrm{min}$ was given to all parturients till the delivery of the baby. Extent of sensory block was assessed by perception of temperature with cold propyl alcohol at 15 seconds interval. Skin incision started when the sensory block is above $\mathrm{T}_{6}$ and after the parturient did not respond to painful stimuli by the operating obstetrician. Modified Bromage scale at 15 minutes post $\mathrm{SAB}$ in each subject were recorded and thereafter at every 15 minutes intervals till Modified Bromage scale 6 was achieved.

\section{Modified Bromage Scale}

\begin{tabular}{|c|c|}
\hline Score & Criteria \\
\hline 1 & Complete block (Unable to move feet to Knee) \\
\hline 2 & Almost complete block (Able to move feet only) \\
\hline 3 & Partial block (Just able to move Knees) \\
\hline 4 & $\begin{array}{c}\text { Detectable weakness of hip flexion while supine } \\
\text { (Full flexion of knees) }\end{array}$ \\
\hline 5 & No detectable weakness of hip flexion while supine \\
\hline 6 & Able to perform partial knee bend \\
\hline
\end{tabular}

Intraoperative vitals were recorded at every 5 minutes interval and episodes of hypotension (mean arterial pressure $<60 \mathrm{~mm} \mathrm{Hg}$ was treated by intravenous (IV) mephentermine, in $3 \mathrm{mg}$ aliquots and bradycardia $<50 / \mathrm{min}$ associated with fall of mean arterial pressure $<60 \mathrm{mmHg}$, by $0.2 \mathrm{mg}$ glycopyrrolate IV. Intraoperative complaints of visceral pain were recorded and treated by judicious use of IV midazolam ( 0.5 to $1 \mathrm{mg}$ ).

Intramuscular (IM) Inj. Oxytocin $10 \mathrm{mg}$ was given just before delivery of the baby and inj. Methylergometrine 0.2 mg IM was given as and when asked by the obstetricians. The baby's Apgar Scores at 5 min of delivery were recorded and compared.

Post-operatively subjects were followed up to the first 24 hours, the time to request the first analgesic was recorded and Inj. Diclofenac Sodium $75 \mathrm{mg}$ IM was given as rescue analgesic and total doses of diclofenac in the first 24 hours were recorded. Side-effects such as nausea \& vomiting and pruritus were recorded and symptomatic treatment with ondansetron and antihistaminics were prescribed whenever required. Serious side-effect of respiratory depression was closely observed, and Injection Naloxone was kept ready for any eventuality. Since all of the subjects were catheterized for the first 24 hours urinary retention as a side effect of intrathecal opioids could not be assessed.

Data were summarized using mean (SD), frequency and proportions. Proportions were compared using Chi square and continuous variables were compared using independent ' $t$ ' test. Data were entered in Microsoft Excel and analysed using IBM SPSS version 21. A p-value of less than 0.05 was considered statistically significant.

Institutional Ethics Committee approved the study. Written informed consent was obtained from each participant. Data were accessible only to the investigators and analysis team.

\section{RESULTS}

Demographic data like age, weight and height of the subjects and base line haemodynamic parameters are expressed as mean \pm standard deviation (SD) \& are shown in Table 1 . There was no statistically significant difference.

\begin{tabular}{|c|c|c|c|}
\hline & $\begin{array}{c}\text { Group I } \\
(\mathbf{n = 3 0 )}\end{array}$ & $\begin{array}{c}\text { Group II } \\
(\mathbf{n = 3 0 )}\end{array}$ & P value \\
\hline $\begin{array}{c}\text { Age mean } \pm \text { SD in } \\
\text { years }\end{array}$ & $30.03 \pm 6.04$ & $30.8 \pm 5.53$ & 0.61 \\
\hline $\begin{array}{c}\text { Weight mean } \pm \text { SD } \\
\text { in kg }\end{array}$ & $68.96 \pm 4.07$ & $67.3 \pm 3.65$ & 0.1 \\
\hline $\begin{array}{c}\text { Height mean } \pm \text { SD } \\
\text { in cm }\end{array}$ & $152.6 \pm 3.14$ & $152.57 \pm 2.71$ & 0.96 \\
\hline $\begin{array}{c}\text { Pulse Rate } \pm \text { SD } \\
\text { (per min) }\end{array}$ & $79.6 \pm 9.49$ & $79.26 \pm 10.01$ & 0.89 \\
\hline $\begin{array}{c}\text { Systolic BP } \pm \text { SD } \\
\text { mmHg }\end{array}$ & $123.23 \pm 7.36$ & $124.23 \pm 6.56$ & 0.58 \\
\hline $\begin{array}{c}\text { Diastolic BP } \pm \text { SD } \\
\text { mmHg }\end{array}$ & $78.13 \pm 5.69$ & $78.86 \pm 5.11$ & 0.60 \\
\hline \multicolumn{3}{|c|}{ Table 1. Demographic Profile \& Baseline Vitals of the } \\
Participants in Study Groups \\
\hline
\end{tabular}

Apgar Score (AS) of the newborns, Intra-operative pulse rates, mean arterial pressure, use of vasopressors and anticholinergics in both the group were comparable and reproduced in Table 2. The median of the AS was 8; none of 
the new born had AS less than 7 at 5 minutes. Two subjects in Group I and 1 subject in Group II had discomfort on exteriorization of uterus and successfully treated with $1 \mathrm{mg}$ Inj. Midazolam IV. There was no statistically significant difference in any of the observations/parameters.

\begin{tabular}{|c|c|c|c|}
\hline & $\begin{array}{c}\text { Group I } \\
(\mathbf{n = 3 0 )}\end{array}$ & $\begin{array}{c}\text { Group II } \\
(\mathbf{n = 3 0 )}\end{array}$ & P value \\
\hline Pulse Rate \pm SD (per min) & $85 \pm 4.2$ & $84 \pm 3.4$ & 0.7 \\
\hline $\begin{array}{c}\text { Mean arterial pressure } \pm \\
\text { SD mmHg }\end{array}$ & $\begin{array}{c}80.52 \pm \\
3.58\end{array}$ & $\begin{array}{c}81.46 \pm \\
4.68\end{array}$ & 0.39 \\
\hline Doses of Mephentermine & 10 & 11 & 0.82 \\
\hline Doses of Glycopyrrolate & 0 & 1 & 0.32 \\
\hline Intra-operative discomfort & 2 & 1 & 0.47 \\
\hline $\begin{array}{c}\text { Apgar Score at 5 } \\
\text { minutes (Median) }\end{array}$ & 8 & 8 & 0.14 \\
\hline Table 2. Intra-Operative Vitals, Use of Vasopressors \& \\
Glycopyrrolate \\
\hline
\end{tabular}

The time to reach T6 level of sensory blockade, Modified Bromage Scale (MBS) at 15 minutes post spinal injection \& the time to reach MBS 6 were noted (Table 3). There was no statistically significant difference in these parameters. The time to request first analgesic and total doses of rescue analgesics in the first twenty-four hours were recorded and showed clinically as well as statistically significant difference; parturients in Group II having much longer pain free period and much lesser doses of rescue analgesic injections.

\begin{tabular}{|c|c|c|c|c|}
\hline & $\begin{array}{c}\text { Group } \\
\text { I }\end{array}$ & $\begin{array}{c}\text { Group } \\
\text { II }\end{array}$ & $P$ value & \begin{tabular}{|c|} 
Statistical \\
Significance
\end{tabular} \\
\hline $\begin{array}{c}\text { Time to reach } \\
\text { sensory block to T6 } \\
\text { (sec) }\end{array}$ & $\begin{array}{c}120.5 \pm \\
19.16\end{array}$ & $\begin{array}{c}114.67 \pm \\
24.08\end{array}$ & 0.31 & NS \\
\hline $\begin{array}{c}\text { Modified Bromage } \\
\text { Score (MBS) at } 15 \\
\text { min (Median) }\end{array}$ & 1 & 1 & 0.75 & NS \\
\hline $\begin{array}{c}\text { Time to First } \\
\text { analgesic (Minutes) }\end{array}$ & $\begin{array}{l}250 \pm \\
51.58\end{array}$ & \begin{tabular}{|l|}
$1022 \pm$ \\
278.63 \\
\end{tabular} & $\begin{array}{c}<0.000 \\
1\end{array}$ & significant \\
\hline $\begin{array}{c}\text { Time to MBS } 6 \\
\text { (Minutes) }\end{array}$ & $\begin{array}{l}125 \pm \\
11.83\end{array}$ & $\begin{array}{c}121.83 \pm \\
24.40\end{array}$ & 0.53 & NS \\
\hline $\begin{array}{c}\text { Total doses of } \\
\text { analgesic in first } \\
24 \mathrm{hr} \\
\end{array}$ & 32 & 3 & $\begin{array}{c}<0.000 \\
1\end{array}$ & significant \\
\hline $\begin{array}{r}\text { Table 3. Char } \\
\text { Blo }\end{array}$ & ens & $f C$ & $y$ and 1 & Iotor \\
\hline
\end{tabular}

The incidence of side effects like nausea \& vomiting, pruritus and respiratory depression were observed up to the first 24 hours (Table 4). Seven subjects in Group I and 6 subjects in Group II had pruritus. There was no incidence of life-threatening side-effects like respiratory depression in both the groups.

\begin{tabular}{|c|c|c|c|c|c|c|}
\hline \multirow{2}{*}{ Complications } & \multicolumn{2}{|c|}{ Group I } & Group II & \multirow{2}{*}{ p } & \multirow{2}{*}{ Significance } \\
\cline { 2 - 7 } & No. & $\%$ & No. & \% & & \\
\hline Nausea\& Vomiting & 6 & 20 & 4 & 13.3 & 0.49 & NS \\
\hline Pruritus & 7 & 23.3 & 6 & 20 & 0.76 & NS \\
\hline $\begin{array}{c}\text { Respiratory } \\
\text { depression }\end{array}$ & 0 & 0 & 0 & 0 & & NS \\
\hline \multicolumn{7}{|c|}{ Table 4. Side Effects } \\
\hline
\end{tabular}

\section{DISCUSSION}

This randomized study was conducted to show the beneficial effects of intrathecal fentanyl and morphine combined with low dose Bupivacaine in caesarean deliveries, utilizing the faster action of intrathecal fentanyl and prolonged analgesic efficacy of intrathecal morphine. There are a number of studies where Fentanyl added to Bupivacaine heavy had shown beneficial effects in terms of rapid onset, smooth maintenance \& extended duration of post-operative analgesia. ${ }^{10}$ Most of the study had employed Fentanyl in the dose of $25 \mu \mathrm{g}$. Intrathecal morphine was first described in 1801 and since the publication on it by Wang JK, et al, in 1979, the popularity of the intrathecal morphine has overgrown tremendously. ${ }^{11}$ There is no evidence that administration of intrathecal morphine in single, repeated or as continuous infusion causes neurotoxicity. In one case report where accidentally $510 \mathrm{mg}(34 \mathrm{ml})$ of morphine was injected intrathecally; naloxone infusion, blood pressure and seizure control led to complete neurological recovery indicating that morphine does not have any neurotoxicity. ${ }^{12}$ In a meta-analysis based on studies on spinal anaesthesia with morphine as an adjuvant of a local anaesthetic, it was documented that with the use of intrathecal morphine at doses $<0.3 \mathrm{mg}$, episodes of respiratory depression was not high as compared to the placebo group who received systemic opioids. ${ }^{13}$

Dhumal PR, et al, ${ }^{14}$ In their study on intrathecal Fentanyl and Bupivacaine combination for caesarean section concluded that addition of low dose preservative free Fentanyl (25 $\mu \mathrm{g}$ ) to $0.5 \%$ hyperbaric Bupivacaine for spinal anaesthesia causes faster onset and satisfactory intraoperative sensory and motor blockade, hemodynamic stability, less side effects and effective postoperative analgesia. Level of sensory blockade and onset of motor blockade were almost similar in all pregnant women in all groups with average T4 [T3-T6] in all groups. In their study they didn't report a high incidence of pruritus. But other studies and meta-analysis of use of intrathecal fentanyl at a dose of $25 \mu \mathrm{g}$ in caesarean sections, the incidence of pruritus was very high ranging from 20 to $100 \%{ }^{15}$

Bogra J et al,16 studied intrathecal Bupivacaine in doses of $8 \mathrm{mg}, 10 \mathrm{mg}$, and $12.5 \mathrm{mg}$ alone or in combination with $12.5 \mu \mathrm{g}$ of fentanyl for Caesarean sections and observed that the onset of sensory block to T6 occurred faster either with increasing Bupivacaine doses or with BupivacaineFentanyl combination groups but with more incidences of hypotension and bradycardia occurring in higher doses of Bupivacaine. But the post-operative analgesia didn't last beyond 80 minutes to 150 minutes post intrathecal injection. However, the incidences of side-effects like nausea \& vomiting and pruritus were very low with the dose of intrathecal Fentanyl.

Kiran S et al, ${ }^{17}$ also studied three doses of Bupivacaine $7.5 \mathrm{mg}, 8.75 \mathrm{mg} \& 10 \mathrm{mg}$ intrathecal doses for caesarean section and observed that increasing Bupivacaine dose increases the time for two segment sensory regression and also the duration of analgesia. But the incidence of hypotension was increased with increasing doses of bupivacaine. In Low dose bupivacaine group women could be made ambulatory at the earliest and also had better hemodynamic stability.

C Sibilla et al ${ }^{18}$ studied combination of $12-14 \mathrm{mg}$ Bupivacaine with Fentanyl $25 \mu \mathrm{g}$ alone or in combination with Morphine $100 \mu \mathrm{g}$ for caesarean sections and could not demonstrate any benefit of combination of both opioids. 
Likewise, Karaman $\mathrm{S}$ et $\mathrm{al},{ }^{19}$ concluded in their study that addition of intrathecal fentanyl $25 \mu \mathrm{g}$ plus intrathecal morphine $100 \mu \mathrm{g}$ to $10 \mathrm{mg}$ bupivacaine for caesarean sections did not show any advantage of the combination and analgesia with only intrathecal morphine and bupivacaine was much superior. In these two studies, they had used a much larger dose of Bupivacaine which alone was more than enough for the procedure and which had masked the rapid onset of subarachnoid blockade initiated by intrathecal fentanyl. Weigl et $\mathrm{al}^{20}$ in a similar study, concluded that combination of Morphine $100 \mu \mathrm{g}$ and $25 \mu \mathrm{g}$ Fentanyl to different doses of Bupivacaine, shortens the incision time and much improved the perioperative analgesia. With intrathecal fentanyl, pain relief is obtained within 10 minutes while intrathecal morphine takes about 60 minutes for onset of its analgesic action. ${ }^{21}$

In our study, we have fully utilized the synergistic effect of intrathecal fentanyl on rapid onset of analgesic sensory blockade and prolonged analgesic effect of intrathecal morphine with reduced dose of Bupivacaine and Fentanyl. A dose of Morphine which is not too high is selected to avoid high incidence of side-effects, to enable early ambulation but to obtain a prolonged pain free post-operative period.

\section{CONCLUSION}

Addition of Fentanyl $16 \mu \mathrm{g}$ and Morphine $125 \mu \mathrm{g}$ to $0.5 \%$ hyperbaric Bupivacaine $7.5 \mathrm{mg}$ was effective for spinal anaesthesia in caesarean section surgeries, with minimal side effects, enabling early ambulation and prolonged analgesia.

Combinations of $7.5 \mathrm{mg} \mathrm{0.5 \%}$ Bupivacaine with Fentanyl $16 \mu \mathrm{g}$ were also beneficial in caesarean section surgeries, with moderate prolongation of analgesia. Addition of opioids such as fentanyl and morphine did not produce any adverse effects either in the mother or the neonate.

\section{REFERENCES}

[1] Clapp MA, Barth WH. The future of cesarean delivery rates in the United States. Clinical Obstetrics and Gynecology 2017;60(4):829-39.

[2] Singh P, Hashmi G, Swain PK. High prevalence of cesarean section births in private sector health facilities- analysis of district level household survey-4 (DLHS-4) of India. BMC Public Health 2018;18(1):613.

[3] Hawkins JL, Koonin LM, Palmer SK, et al. Anesthesiarelated deaths during obstetric delivery in the United States, 1979-1990. Anesthesiology 1997;86(2):27784.

[4] Yeoh SB, Leong SB, Heng AS. Anaesthesia for lowersegment caesarean section: changing perspectives. Indian J Anaesth 2010;54(5):409-14.

[5] Fogarty DJ, Carabine UA, Milligan KR. Comparison of the analgesic effects of intrathecal clonidine and intrathecal morphine after spinal anaesthesia in patients undergoing total hip replacement. $\mathrm{Br} J$ Anaesth 1993;71(5):661-4.

[6] Bi YH, Cui XG, Zhang RQ, et al. Low dose of dexmedetomidine as an adjuvant to bupivacaine in cesarean surgery provides better intraoperative somato-visceral sensory block characteristics and postoperative analgesia. Oncotarget 2017;8(38):63587-95.
[7] Kumar K, Singh SI. Neuraxial opioid-induced pruritus: an update. J Anaesthesiol Clin Pharmacol 2013;29(3):303-7.

[8] Etches RC, Sandler AN, Daley MD. Respiratory depression and spinal opioids. Can J Anaesth 1989;36(2):165-85.

[9] Wang JK, Nauss LA, Thomas JE. Pain relief by intrathecally applied morphine in man. Anesthesiology 1979;50(2):149-51.

[10] Weigl W, Bieryło A, Wielgus M, et al. Analgesic efficacy of intrathecal fentanyl during the period of highest analgesic demand after cesarean section: a randomized controlled study. Medicine (Baltimore) 2016;95(24):e3827.

[11] DeSousa KA, Chandran R. Intrathecal morphine for postoperative analgesia: current trends. World J Anesthesiol 2014;3(3):191-202.

[12] Yilmaz A, Sogut A, Kílinc M, et al. Successful treatment of intrathecal morphine overdose. Neurol India 2003;51(3):410-11.

[13] Giovannelli M, Bedforth N, Aitkenhead A. Survey of intrathecal opioid usage in the UK. Eur J Anaesthesiol 2008;25(2):118-22.

[14] Dhumal PR, Kohle EP, Gunjal VB, et al. Synergistic effect of intrathecal fentanyl and bupivacaine combination for cesarean section. Int J Pharm Biomed Res 2013;4.

[15] Ko MC. Neuraxial opioid-induced itch and its pharmacological antagonism. Handb Exp Pharmacol 2015;226:315-35.

[16] Bogra J, Arora N, Srivastava P. Synergistic effect of intrathecal fentanyl and bupivacaine in spinal anesthesia for caesarean section. BMC Anesthesiology 2005;5(1):5.

[17] Kiran S, Singal NK. A comparative study of three different doses of $0.5 \%$ hyperbaric Bupivacaine for spinal anaesthesia in elective caesarean section. International Journal of Obstetric Anesthesia 2002;11(3):185-9.

[18] Sibilla C, Albertazz P, Zatelli R, et al. Perioperative analgesia for caesarean section: comparison of intrathecal morphine and fentanyl alone or in combination. International Journal of Obstetric Anesthesia 1997;6(1):43-8.

[19] Karaman S, Günüsen I, Uyar M, et al. The effects of morphine and fentanyl alone or in combination added to intrathecal bupivacaine in spinal anesthesia for cesarean section. Agri 2011;23(2):57-63.

[20] Weigl W, Bieryło A, Wielgus M, et al. Perioperative analgesia after intrathecal fentanyl and morphine or morphine alone for cesarean section - a randomized controlled study. Medicine 2017;96(48):e8892.

[21] Cosgrave D, Shanahan E, Conlon N. ATOTW 347 Intrathecal Opioids. 21st Feb 2017. 